\title{
Physiological tests for early detection of rigid ryegrass (Lolium rigidum Goud.) resistance to fenoxaprop-P
}

\author{
Diana Saja $\cdot$ Magdalena Rys $\cdot$ Agnieszka Stokłosa $\cdot$ \\ Andrzej Skoczowski
}

Received: 27 May 2013/Revised: 18 October 2013/Accepted: 21 October 2013/Published online: 30 October 2013

(C) The Author(s) 2013. This article is published with open access at Springerlink.com

\begin{abstract}
The study aimed to determine the usefulness of isothermal calorimetry and FT-Raman spectroscopy for the early evaluation of rigid ryegrass resistance to fenoxaprop$\mathrm{P}$ ethyl (active ingredient one of aryloxyphenoxypropionate herbicides). The calorimetric measurements were done on the 4-day-old seedlings of susceptible and resistant biotypes of rigid ryegrass (Lolium rigidum Goud.) for $72 \mathrm{~h}$, at $20{ }^{\circ} \mathrm{C}$. It was observed that the specific thermal powertimecurves of the susceptible and resistant biotypes growing on water (control) were qualitatively similar. Herbicides changed the shape of the specific thermal power-time curves of both biotypes. Furthermore, the total specific thermal energy was significantly higher for the seedlings of resistant biotype, growing both on water or herbicide, as compared to the susceptible ones. The analysis of the seedlings' endosperm, conducted using FT-Raman spectroscopy, showed a weaker intensity of the bands in the spectra derived from the resistant biotype. Differences in the specific thermal power-time curves and FT-Raman spectra between susceptible and resistant biotypes growing on water indicate that the sensitive and resistant biotypes
\end{abstract}

Communicated by W. Filek.

D. Saja

Department of Biology, Pedagogical University of Cracow, Podchorążych 2, 30-084 Krakow, Poland

M. Rys $(\bowtie) \cdot$ A. Skoczowski

The Franciszek Górski Institute of Plant Physiology, Polish Academy of Science,

Niezapominajek 21, 30-239 Krakow, Poland

e-mail: mtroc@ifr-pan.krakow.pl

A. Stokłosa

Department of Agriculture and Economics, University of Agriculture, Mickiewicza 21, 31-120 Krakow, Poland are metabolically and chemically different already in the early stages of the seedling growth. We conclude that isothermal calorimetry and FT-Raman spectroscopy are efficient tools for the early detection of rigid ryegrass resistance to fenoxaprop-P ethyl.

Keywords Fenoxaprop-P ethyl · FT-Raman spectroscopy · Isothermal calorimetry · Resistance to herbicides · Rigid ryegrass

\section{Introduction}

In modern agriculture a vast number of herbicides are commonly used to efficiently control both monocot and dicot weeds. Despite the clear advantages of chemical weed control, many drawbacks are also associated with herbicide usage including the serious issue of herbicide resistance (Kudsk and Streibig 2003). By definition, herbicide resistance is the inherited ability of a plant to survive and reproduce following exposure to a dose of herbicide that would normally be lethal to its wild type (Parther et al. 2000). Problem of weed resistance to herbicides is worldwide and relates to 217 species: 129 dicots and 88 monocots, in more than 50 countries (Heap 2012). Among resistant biotypes one of the largest and most important groups are the monocots resistant to graminicides, especially Alopecurus myosuroides L., Avena fatua L. and Lolium rigidum Goud. (Mortimer 1993). Each of these species exhibits resistance to HRAC (Herbicide Resistance Action Committee) group A herbicides, inhibitors of lipid synthesis, so-called FOPs and DIMs (Menne 2012). With a growing number of resistant weed biotypes appearing, the development of methods that screen for resistance is becoming increasingly important. According to Moss 
(1999) "diagnostic tests should be rapid, accurate, cheap, readily available and give a reliable indication of the likely impact of resistance on herbicide activity in the field". To date, a limited number of screening methods for graminicide resistance have been introduced. Of the methods that are available, the most common is the "Rothamsted Rapid Resistance Test" introduced by Moss (2000). The test involves germinating weed seeds in dilute herbicide solutions and then assessing resistance after 2 weeks of seedling growth. The "Syngenta Quick Test" presented by Boutsalis (2001) evaluates resistance by collecting cuttings from weeds that have survived herbicide application, transplanting the cuttings into pots and allowing them to regenerate, subjecting them to further herbicide application, then visually evaluating leaf damage 10 days after herbicide treatment. Scientists from Laboratoire d'Agronomie-Malherbologie INRA in Dijon have also developed three different tests to assess grasses resistant to graminicides. The first test is based upon the differences in the coleoptile length of resistant and susceptible grasses after 6 days of growth in the presence of single solutions of fenoxaprop-P acid or diclofop acid (Letouze and Gasquez 1999). The second test examines germination of pollen in the presence of agar medium containing fenoxaprop or diclofop, where inhibition of pollen growth is observed after $2 \mathrm{~h}$ (Letouze and Gasquez 2000). The third test utilizes PCR to distinguish isoleucine-leucine substitution in populations of resistant grasses giving results within a day (Delye et al. 2002). Two other physiological methods have been proposed for the same group of herbicides, one testing the activity of purified ACC-ase from resistant and susceptible biotypes of ryegrass treated with graminicides (De Prad et al. 2000) and the other using the application of isothermal calorimetry for the early detection of resistance to fenoxaprop-P and diclofop in wild oat (A. fatua L.) (Stokłosa et al. 2006).

While methods are available to assess the resistance of grassy weeds to graminicides, a need for new and faster methods, particularly those exploring the physiological processes involved in resistance, still remains. Given this need, the proposed method by Stokłosa et al. (2006) utilizing isothermal calorimetry to assess resistance appears promising. Recently, isothermal calorimetry has become increasingly used in the plant stress physiology (Skoczowski and Troć 2013). For example isothermal calorimetry has been applied to study the response of plants to salinity (Schabes and Sigstad 2005; Baltruschat et al. 2008) and in allelopathy (Schabes and Sigstad 2007; Kupidlowska et al. 2006) or host-pathogen interactions (Janeczko et al. 2007; Fodor et al. 2007). In this paper we propose to further develop the method using isothermal calorimetry by combining it with Fourier transformed Raman (FT-Raman) spectroscopy to expand the scope of physiological measurements that can be carried out on resistant biotypes. Raman spectroscopy is a laser-based vibrational technique for the analysis of molecular bonds due to inelastic scattering of photons. Raman-scattered photons are scattered predominantly with a shift toward longer wavelengths, whereby they deposit parts of their energy in the sample. The differences between the incident and scattered frequencies correspond to the energy of the molecular vibrations. Therefore, a Raman spectrum is a "molecular fingerprint" of the sample, providing rich information about chemical bonds associated with DNA, proteins, lipids and carbohydrates commonly found in biological samples (Peticolas 1995). FT-Raman spectroscopic methods are applied to the analysis of valuable plant substances or quality parameters in horticultural and agricultural crops (Schulz and Barańska 2007) and in plant stress physiology (Skoczowski and Troć 2013). In our team the FTRaman spectroscopy method has previously been successfully applied to study the chemical changes in the cotyledons of mustard seedlings induced by allelophatic factors (Troć et al. 2009).

This study examines the impact of fenoxaprop-P on the intensity of metabolism of rigid ryegrass ( $L$. rigidum Gaud.) biotypes, differing in the resistance level to this herbicide. The physiological and biochemical differences between biotypes, linked to the resistance to fenaxoprop-P, were searched.

\section{Materials and methods}

\section{Plant sources}

A resistant biotype RG99-008 of rigid ryegrass ( $L$. rigidum Gaud.), a $100 \%$ ACC-ase Leu 1781 mutant (received from Dr. H. Darmency, INRA, Dijon), was studied. ACC-ase Leu 1781 mutant means that the biotype has an amino acid substitution in plastid ACC-ase, conferring resistance to ACC-ase inhibitor type of herbicides (Liu et al. 2007). As a comparison, a susceptible population of $L$. rigidum, collected from organic fields (in this field have not been applied herbicides) in the Małopolska region, was used.

The commercial herbicide Puma Uniwersal 069 EW (Bayer CropScience), containing the active ingredient: ethyl (R)-2-[4-(6-chloro-1,3-benzoxazol-2-yloxy)phenoxy]propionate (common name: fenoxaprop-P ethyl, $\left.0.69 \mathrm{~g}^{-1}\right)$ and mefenpyr diethyl $\left(75 \mathrm{~g} \mathrm{l}^{-1}\right.$, as herbicide safener), was used in the experiment. One dose of herbicide, equal to $152.3 \%$ of the field dose of Puma Uniwesal $069 \mathrm{EW}$, was used in the measurements following the procedure outlined by Stokłosa et al. (2006). 
Calorimetric measurements

The experiment was conducted on young seedlings of resistant and susceptible ryegrass biotypes. Seeds were germinated on distilled water in Petri dishes, equipped with two layers of Whatmann No. 2 filter paper for $96 \mathrm{~h}$ at $20{ }^{\circ} \mathrm{C}$ in darkness. Morphologically similar seedlings (about $3 \mathrm{~mm}$ coleoptile length) were chosen for use in the experiment. Heat released from the seedlings was measured in an isothermal calorimeter (TAM III 3101, TA Instruments) at $20^{\circ} \mathrm{C}$. Twenty cubic centimeter ampoules equipped with lids which enable natural air exchange were used. Three ryegrass seedlings were placed in each ampoule, on filter paper moistened with $150 \mu \mathrm{l}$ of herbicide's solution (equal to $152.3 \%$ of the filed dose), following the procedure described by Stokłosa et al. (2006). The ampoules were allowed to equilibrate for $30 \mathrm{~min}$ and then placed in the measurement chamber. The reference ampoule contained only the filter paper moistened with the herbicide's solution. As a control, the seedlings placed on filter paper moistened with $150 \mu \mathrm{l}$ of distilled water were used. The measurements of heat were recorded continuously for $72 \mathrm{~h}$ in $20^{\circ} \mathrm{C}$. Each treatment was repeated five times. The thermal power was calculated per gram of dry weight.

The calorimetric measurements were subjected to oneway ANOVA, using STATISTICA 9.0 for Windows software (Statsoft Inc. 2010). To determine the significance of differences the post hoc Duncan test at $p=0.05$ was used.

\section{Measurements of FT-Raman spectroscopy}

The same seedlings which were used in the calorimetric measurements were studied further by FT-Raman spectroscopy. FT-Raman spectra were recorded using a Nicolet NXR 9650 FT-Raman Spectrometer equipped with a $\mathrm{Nd}$ :YAG laser emitting at $1,064 \mathrm{~nm}$ and a germanium detector, cooled with liquid nitrogen. The measurements were performed with a spectral resolution of $4 \mathrm{~cm}^{-1}$ in the range of $100-4,000 \mathrm{~cm}^{-1}$. All spectra were accumulated from 128 scans, measured with a laser power of $200 \mathrm{~mW}$, using an unfocused laser beam with a diameter of $\sim 100 \mu \mathrm{m}$. Raman spectra were recorded by the Omnic/ Thermo Scientific software program. For each treatment five spectra were collected.

Cluster analysis is used to quantify the samples under their chemical composition. The result is obtained as a dendrogram (tree). The larger the distance between the objects (branches of the tree), greater the differences in their chemical composition. Hierarchical cluster analysis was performed for the FT-Raman spectra using the Opus/ Bruker package (5.1). The cluster analysis was performed separately for water controls and herbicide treatments, on the averaged spectra for wave number ranges, using Ward's algorithm.

\section{Results and discussion}

The heat production

Typical specific thermal power-time curves for the seedlings of the susceptible and the resistant biotype of ryegrass growing on water or on herbicide are shown in Fig. 1a, b respectively. It was observed, that the specific thermal power-time curves of the susceptible and resistant biotypes growing on water (control) were qualitatively similar. Herbicides changed the shape of the specific thermal power-time curves of both biotypes. Specific thermal power-time curves for subjects treated with herbicide are different, not only in shape, but also in the absolute values. Curves obtained for seedlings of susceptible biotype after treatment with herbicide never reached levels observed in the control seedlings growing on water (Fig. 1a). Whereas, in resistant biotype was an increase of the values of specific thermal power over the values obtained for control (Fig. 1b). Furthermore, in the case of seedlings of susceptible biotype treated with herbicide, after the peak in the specific thermal power curve plateau was observed (Fig. 1a), whereas in resistant biotype followed the growth of thermal power values (Fig. 1b).

The total amount of specific heat energy produced by seedlings of rigid ryegrass was significantly different for all the combinations tested (Fig. 2). Overall, a significantly higher amount of specific heat energy was produced by the resistant biotype, regardless of the water or herbicide treatment. Resistant seedlings growing on water produced in total $2,200 \mathrm{~J} \mathrm{~g}_{\mathrm{DW}}^{-1}$ of heat energy, which was by about $600 \mathrm{~J} \mathrm{~g} \mathrm{gW}_{\mathrm{DW}}^{-1}$ more as compared to the seedlings of the susceptible biotype.

In general application of fenoxaprop-P caused reduction of the amount of produced heat energy (Fig. 2). Still, the reduction in heat was lower for the resistant biotype, as compared to the susceptible one. The amount of heat produced by the susceptible biotype was by about $60 \%$ lower, compared to its control, whereas in the resistant biotype the decrease was of $30 \%$, when compared to the resistant control (Fig. 2). Our research carried out on rigid ryegrass ( $L$. rigidum Gaus.) showed the metabolic differences between resistant and susceptible biotype, which were noted in the first $48 \mathrm{~h}$ of heat flow measurement. The similar findings, relating to the differences in the heat flow between wild oat biotypes resistant and susceptible to APP herbicides, were made by Stokłosa et al. (2006), and earlier, for Avena sterilis L., by Maneechote et al. (1997). We have also shown the differences in the values of specific 
Fig. 1 Typical specific thermal power-time curves for the seedlings of susceptible biotype (A) and resistant biotype (B) of ryegrass growing on water (control) and fenoxaprop-P (herbicide). By straight lines marked the trends changes in thermal power-time curves of biotypes treated with herbicide

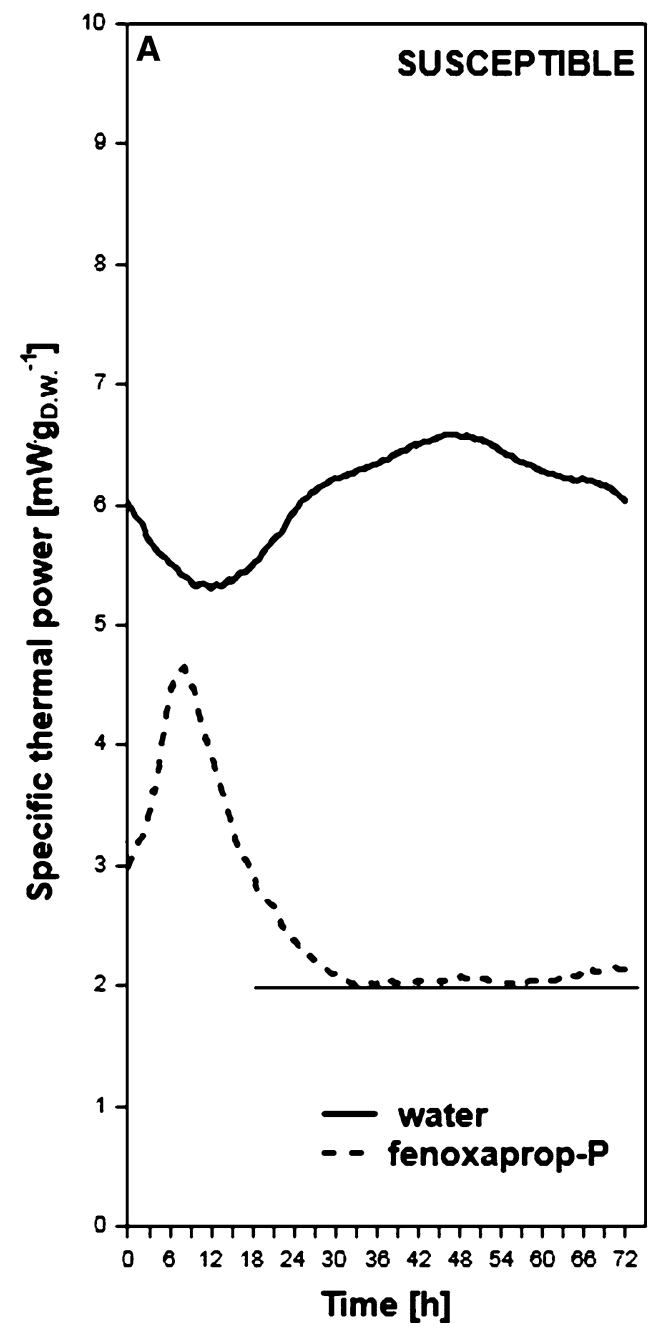

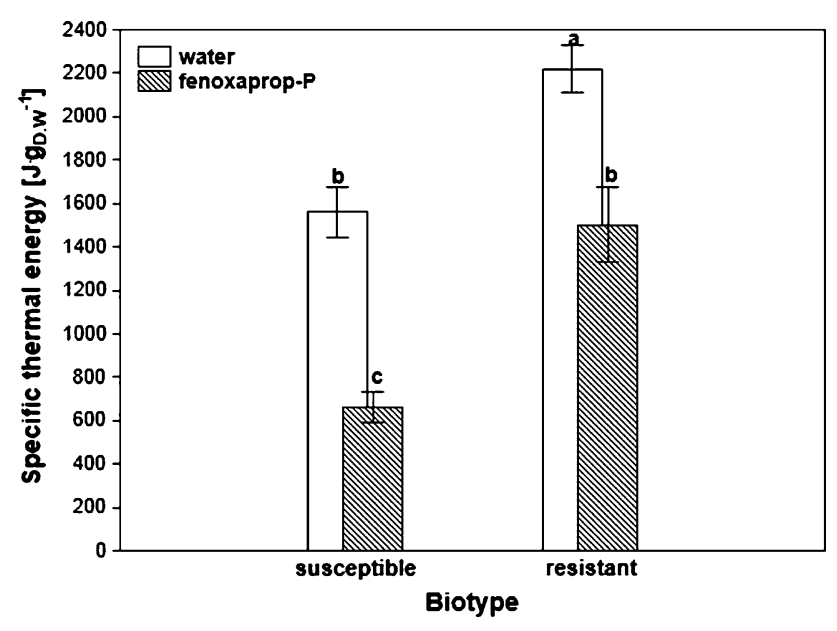

Fig. 2 Total amount of specific thermal energy produced by seedlings of susceptible and resistant biotype of rigid ryegrass during their growth on water (control) and fenoxaprop-P (herbicide). Means values for 5 replications $\pm \mathrm{SD}$. Bars denoted the same letter are not significantly different according to Duncan's multiple range test at $p \leq 0.05$ thermal power between resistant and susceptible biotypes growing on water (controls), as the shape, as well as the amounts of produced heat energy, are significantly different. This indicates that the resistance to herbicides is associated with changes in the metabolism of plants already visible in the early stages of seedling growth. Our results also proved that the used dose of herbicide fenoxaprop-P (152.3\% of the field dose) clearly distinguishes the metabolic activity between resistant and susceptible biotypes of rigid ryegrass.

The shape of the thermal power-time curves for rigid ryegrass treated with fenoxaprop-P was similar only in susceptible biotype (Stokłosa et al. 2006).

Moreover, the significantly higher heat amount released by resistant ryegrass seedlings, as compared to the susceptible biotype was similar to those results obtained by Stokłosa et al. (2006) for wild oat. This confirms a hypothesis, suggested by Stokłosa et al. (2006), that an increased amount of specific thermal power released by the resistant biotypes is the effect of metabolic activity, 


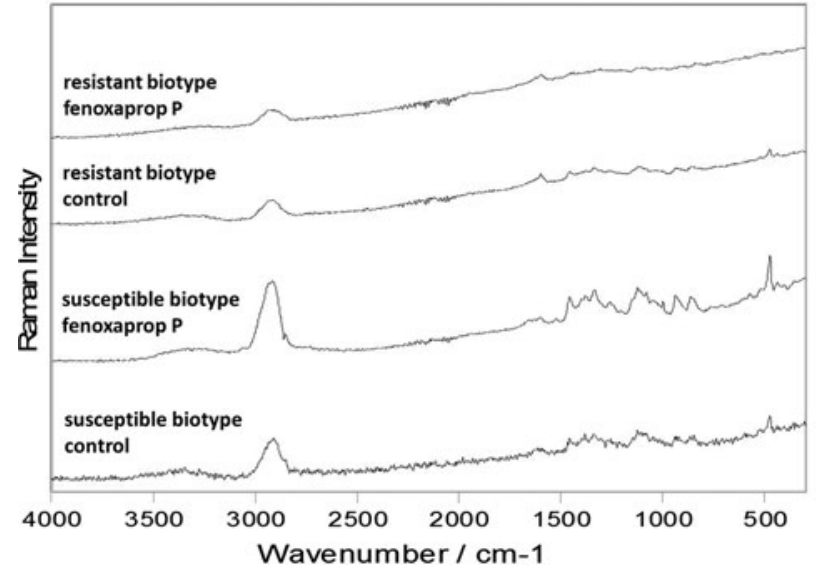

Fig. 3 FT-Raman spectra of rigid ryegrass endosperm of susceptible and resistant biotype germinated on water (control) and fenoxaprop-P (herbicide)

resulting from defense against stress caused by the herbicide.

The biotypes of rigid ryegrass, examined in our study, displayed increased metabolic activity during the first $8-12 \mathrm{~h}$ of growth in the presence of herbicide, whereas wild oat previously showed an increase in activity after $10-20 \mathrm{~h}$ of growth in the presence of fenoxaprop-P (Stokłosa et al. 2006). Nonetheless, both findings confirm that the calorimetric method used for screening grasses resistant to fenoxaprop-P, gives reliable results in a relatively short period of time after exposure to the herbicide.

Chemical composition of resistant and susceptible endosperm

The intensity of the spectrum, measured using Raman method, was visibly weaker for the resistant biotype, in comparison to the susceptible one (Fig. 3). Furthermore, the shapes of the spectra curves for both biotypes, susceptible and resistant, were similar. Stretching vibrations, originating from the groups $-\mathrm{CH},-\mathrm{CH}_{2}$ and $-\mathrm{CH}_{3}$, near $3,000 \mathrm{~cm}^{-1}$, were observed in both biotypes, although their intensity was more than twice as high in the sensitive biotype. The band which appeared at about $1,450-1,300 \mathrm{~cm}^{-1}$ in Raman spectra is seemingly also present in herbicide treated resistant line, but in low amount, came from deformation vibrations of groups $-\mathrm{CH}$, $-\mathrm{CH}_{2}$ and $-\mathrm{CH}_{3}$ and stretching vibrations $\mathrm{C}-\mathrm{C}$ of aliphatic carbohydrates, respectively. These bands were absent in the resistant biotype treated by herbicide. Additionally, the bands arising from the aromatic ring stretch doubled at about 1,600 and $1,660 \mathrm{~cm}^{-1}$ in connection with the ring breathing at 1,190 and $1,215 \mathrm{~cm}^{-1}$ which are both visible on the spectra. At about $1,100 \mathrm{~cm}^{-1}$ bands showing the presence of cellulose and lignin were observed. Below

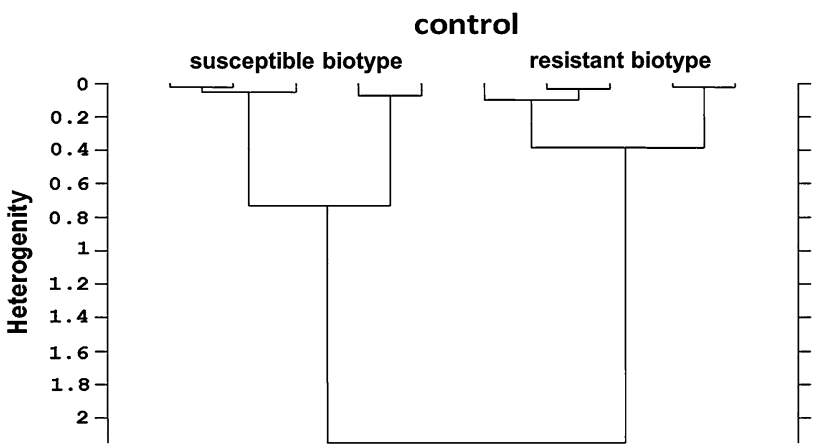

Fig. 4 Dendrogram showing classification of susceptible and resistant biotype of rigid ryegrass endosperm treated with water (control) after cluster analysis of the FT-Raman spectra using the Ward's algorithm for calculating spectral distances. Each branch represents a spectrum obtained from measurements made for different endosperms

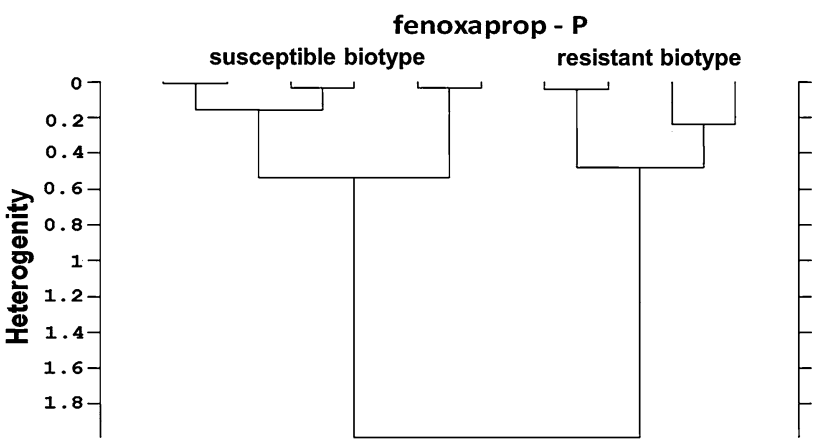

Fig. 5 Dendrogram showing classification of susceptible and resistant biotype of rigid ryegrass endosperm treated with fenoxaprop-P (herbicide) after cluster analysis of the FT-Raman spectra using the Ward's algorithm for calculating spectral distances. Each branch represents a spectrum obtained from measurements made for different endosperms

$1,000 \mathrm{~cm}^{-1}$ bands coming from polysaccharides were observed, while at about $700 \mathrm{~cm}^{-1}$ bands derived from pectin were noted and at about $500 \mathrm{~cm}^{-1}$ bands from starch. The above bands were also seen, but to a much lesser extent, in the control seedlings of the resistant biotype, but were invisible in the case of the resistant biotype treated with herbicide (Fig. 3).

Some changes can be seen in the chemical composition, displayed by the intensities of Raman bands originating from the different biotypes. So, a correlation between intensity of signal and the concentration of analyte is present in a sample. The cluster analysis, carried out on the averaged spectra at wavenumber between 420 and 3,519, indicated the various contents of the components (Fig. 4). As a result a different character of both rigid ryegrass biotypes, resistant and susceptible, regardless of their reaction to the treatment (water or herbicide) was proved. The differences in the chemical composition of endosperm between the resistant and susceptible biotypes were noted 
both during growth on water (Fig. 4) or on the herbicide (Fig. 5). In both cases, the resistant and susceptible biotypes represent clearly distinct groups, which confirm the significant differences in the chemical composition of their endosperm. At the same time more visible differences were observed when biotypes grew on water (Fig. 4).

In our study the Raman spectroscopy technique was used for the first time to assess the differences in the chemical composition of endosperm between resistant and susceptible rigid ryegrass biotypes. This technique is useful for characterizing and identifying chemical compositions in living tissue. This allows the study of chemical compounds in situ in their natural environment, which is not possible when using other analytical techniques (Schrader et al. 1999, 2000). The obtained results showed a visible heterogeneity between biotypes differing in their susceptibility to fenoxaprop-P, indicating low-intensity bands in the case of the resistant biotype. This may result from the lack of tissue homogeneity. Compounds present in the resistant seedlings in small amounts or located at specific points in the tissue could have been undetected or their presence in the sample may have been lost in the sample noise. This could result from the point measurements, and could be solved using Raman mapping technique, carried out on the whole surface of tested plant material (Troć et al. 2009). Nonetheless, some differences in the intensities of Raman bands originating from susceptibility level to fenoxaprop-P were noted, which indicated variations in the content of chemical compounds, especially carbohydrates in the plant tissues. Carbohydrates belong to the main storage materials in the grains of ryegrass. The higher content of carbohydrates in the tissues of susceptible biotype could be due to decomposition of polysaccharides, such as starch and sucrose, into simple sugars, under the influence of the applied herbicide. Similar changes have been observed after the application of allelochemicals to the mustard seed cotyledons (Troć et al. 2009; Skoczowski et al. 2011).

In order to find meaningful and systematic differences between the measured spectra of Lolium endosperm of the resistant and susceptible biotype, cluster analysis was performed. Cluster analysis confirmed the results of the calorimetric and Raman measurements, indicating the clear differences between the resistant and susceptible biotypes, regardless of their treatment (control or herbicide). The differences in the chemical composition of the endosperm of the susceptible and resistant biotype seedlings were confirmed. The cluster analysis, based on the chemical composition of plant material, proved to be effective in demonstrating the difference between the resistant and susceptible rigid ryegrass biotypes, and thus create a new method to quickly identify a developed resistance to herbicides.

\section{Conclusions}

We have proved that isothermal calorimetry is a possibly useful method for early detection of rigid ryegrass resistance to fenoxaprop-P. Calorimetric monitoring of seedling growth is a rapid test, which allows for the indication of significant differences in the specific thermal power and specific heat energy between resistant and susceptible rigid ryegrass biotypes. In addition, FT-Raman spectroscopy method could be useful for estimating the heterogeneity of the chemical composition of the endosperm in susceptible and resistant biotypes of rigid ryegrass.

Author contribution D. Saja carried out the calorimetric experiments, analysed data and wrote the calorimetric part of the manuscript. M. Rys carried out the FT-Raman spectroscopy experiments, analysed data and wrote the FTRaman spectroscopy part of the manuscript. A. Stokłosa wrote the introduction of manuscript and made suggestions to the manuscript. A. Skoczowski designed the experiments and made suggestions to the manuscript.

Acknowledgments We would like to thank Dr H. Darmency, from INRA in Dijon, for providing us with seeds of resistant biotype.

Open Access This article is distributed under the terms of the Creative Commons Attribution License which permits any use, distribution, and reproduction in any medium, provided the original author(s) and the source are credited.

\section{References}

Baltruschat H, Fodor J, Harrach BD, Niemczyk E, Barna B, Gullner G, Janeczko A, Kogel KH, Schäfer P, Schwarczinger I, Zuccaro A, Skoczowski A (2008) Salt tolerance of barley induced by the root endophyte Piriformospora indica is associated with a strong increase in antioxidants. New Phytol 180:501-510

Boutsalis P (2001) Syngenta quick-test: a rapid whole-plant test for herbicide resistance. Weed Technol 15:257-263

De Prad R, Gonalez-Gutierrez J, Menendez J, Gasquez J, Gronwald JW, Gimenez-Espinosa R (2000) Resistance to acetyl CoA carboxylase-inhibiting herbicides in Lolium multiflorum. Weed Sci 48:311-318

Delye Ch, Matejicek A, Gasquez J (2002) PCR-based detection of resistance to acetyl-CoA carboxylase-inhibiting herbicides in black-grass (Alopecurus myosuroides Huds) and ryegrass (Lolium rigidum Gaud). Pest Manag Sci 58:474-478

Fodor J, Harrach B, Janeczko A, Barna B, Skoczowski A (2007) Metabolic responses of tobacco to introduction of systemic acquired resistance. Thermochim Acta 466:29-34

Heap (2012) International survey of herbicide resistant weeds available. www.weedscience.org/In.asp. Accessed 26 June 2012

Janeczko A, Tobias I, Skoczowski A, Dubert F, Gullner G, Barna B (2007) Bacterial infection and pre-treatment with 24-epibrassinolide markedly affect the heat emission and membrane permeability of rape cotyledons. Thermochim Acta 458:88-91

Kudsk P, Streibig JC (2003) Herbicides-a two-edged sword. Weed Res 43:90-102 
Kupidłowska E, Gniazdowska A, Stępień J, Corbineau F, Ginel D, Skoczowski A, Janeczko A, Bogatek R (2006) Impact of sunflower (Helianthus annuus L.) extracts upon reserve mobilization and energy metabolism in germinating mustard (Sinapis alba L.) seeds. J Chem Ecol 32:2569-2583

Letouze A, Gasquez J (1999) A rapid reliable test for screening aryloxyphenoxypropionic acid resistance within Alopecurus myosuroides and Lolium spp. populations. Weed Res 39:37-48

Letouze A, Gasquez J (2000) A pollen test to detect ACCase targetsite resistance within Alopecurus myosuroides populations. Weed Res 40:151-162

Liu W, Harrison DK, Chalupska D, Gornicki P, O'Donnell ChC, Atkins SW, Haselkom R, Williams RR (2007) Single-site mutations in the carboxyltransferase domain of plastid acetylCoA carboxylase confer resistance to grass-specific herbicides. Proc Natl Acad Sci USA 104(9):3627-3632. doi: 10.1073/pnas. 0611572104

Maneechote C, Preston C, Powles SB (1997) A diclofop-methylresistant Avena sterilis L. biotype with a herbicide-resistant acetyl-coenzyme A carboxylase and enhanced metabolism of diclofop-methyl. Pestic Sci 49:105-114

Menne H (2012) Classification of herbicides According to Site of Action. http://hracglobal.com/Publications/Classificationof HerbicideSiteofAction/tabid/222/Default.aspx. Accessed 26 June 2012

Mortimer AM (1993) A review of graminicide resistance. http:// hracglobal.com/Publications/AReviewofGraminicideResistance/ tabid/223/Default.aspx. Accessed 26 June 2012

Moss SR (1999) Detecting herbicide resistance. http://hracglobal. com/Publications/DetectingHerbicideResistance/tabid/229/Default. aspx. Accessed 26 June 2012

Moss SR (2000) The "Rothamsted Rapid Resistance Test" for detecting herbicide-resistance in annual grass-weeds. Weed Sci Soc Am Abstr 40:102

Parther TS, Ditomaso JM, Holt JS (2000) Herbicide resistance: definition and management strategies. Publication 8012. ANR Publications, California, p 14
Peticolas WL (1995) Raman spectroscopy of DNA and proteins. Biochem Spectr 246:389-416

Schabes FI, Sigstad EE (2005) Calorimetric studies of quinoa (Chenopodium quinoa Willd.) seed germination under saline stress conditions. Thermochim Acta 428:51-71

Schabes FI, Sigstad EE (2007) A calorimetric study of the allelopathic effect of chinin isolated from Centaurea diffusa Lam. on the germination of soybean (Glicine max) and radish (Raphanus sativus). Thermochim Acta 458:84-87

Schrader B, Klump HH, Schenzel K, Schulz H (1999) Nondestructive NIR FT Raman analysis of plants. J Mol Str 509:201-212

Schrader B, Schulz H, Andreev GN, Klump HH, Sawatzki J (2000) Non-destructive NIR-FT-Raman spectroscopy of plant and animal tissues, of food and works of art. Talanta 53:35-45

Schulz H, Barańska M (2007) Identification and quantification of valuable plant substances by IR and Raman spectroscopy. Vib Spectr 43:13-25

Skoczowski A, Troć M (2013) Isothermal calorimetry and Raman spectroscopy to study response of plants to abiotic and biotic stress. In: Ranjan RG, Bandhu DA (ed) Molecular stress physiology of plants. Springer, ISBN 978-81-322-0806-8, pp 263-288

Skoczowski A, Troć M, Baran A, Barańska M (2011) Impact of sunflower and mustard leave extracts on the growth and dark respiration of mustard seedlings. J Therm Anal Calorim 104:187-192

Statsoft Inc. (2010) STATISTICA (data analysis software system) Version 9 www.statsoft.com

Stokłosa A, Janeczko A, Skoczowski A, Kieć J (2006) Isothermal calorimetry as a tool for estimating resistance of wild oat (Avena fatua $\mathrm{L}$.) to aryloxyphenoxypropionate herbicides. Thermochim Acta 411:203-206

Troć M, Skoczowski A, Barańska M (2009) The influence of sunflower and mustard leaf extracts on the germination of mustard seeds. J Therm Anal Cal 95:727-730 